\title{
Visualization of transcoronary ablation of septal hypertrophy in patients with hypertrophic obstructive cardiomyopathy: a comparison between cardiac MRI, invasive measurements and echocardiography
}

\author{
Christian Sohns $\cdot$ Samuel Sossalla $\cdot$ Jan D. Schmitto Claudius Jacobshagen • \\ Björn W. Raab · Silvia Obenauer · Lars S. Maier
}

Received: 1 November 2009/Accepted: 22 January 2010/Published online: 21 February 2010

(C) The Author(s) 2010. This article is published with open access at Springerlink.com

\begin{abstract}
Objective Hypertrophic obstructive cardiomyopathy (HOCM) is treated by surgical myectomy or transcoronary ablation of septal hypertrophy (TASH). The aim of this study was to visualize the feasibility, success and short-term results of TASH on the basis of cardiac MRI (CMR) in comparison with cardiac catheterization and echocardiography.

Methods In this in vivo study, nine patients with HOCM were treated with TASH. Patients were evaluated by transthoracic echocardiography, invasive cardiac angiography and CMR. Follow-up examinations were carried out after 1, 3 and 12 months. MR imaging was performed on a 1.5-T scanner. All images were processed using the semiautomatic Argus software and were evaluated by an attending thoracic radiologist and cardiologist.

Results The echocardiographic pressure gradient (at rest) was $69.3 \pm 15.3 \mathrm{mmHg}$ before and $22.1 \pm 5.7 \mathrm{mmHg}$ after TASH $(P<0.01, n=9)$. The flux acceleration over the aortic valve examined $\left(V_{\max }\right)$ was $5.1 \pm 0.6 \mathrm{~m} / \mathrm{s}$ before and
\end{abstract}

S. Obenauer and L. S. Maier, contributed equally.

C. Sohns $\cdot$ S. Sossalla $\cdot$ J. D. Schmitto $\cdot$ C. Jacobshagen ·

B. W. Raab $\cdot$ S. Obenauer $\cdot$ L. S. Maier $(\bowtie)$

Department of Cardiology and Pneumology/Heart Center, Georg-August-University Goettingen, Robert-Koch-Str. 40,

37075 Goettingen, Germany

e-mail: 1maier@med.uni-goettingen.de

\section{J. D. Schmitto}

Division of Cardiac Surgery,

Brigham and Women's Hospital,

Harvard Medical School, Boston, USA

B. W. Raab $\cdot$ S. Obenauer

Department of Radiology,

Georg-August-University Goettingen, Goettingen, Germany
$3.4 \pm 0.3 \mathrm{~m} / \mathrm{s}$ after the TASH procedure $(P<0.05)$. Also, there was a decrease of septum thickness from $22.0 \pm 1.2$ to $20.2 \pm 1.0 \mathrm{~mm}(P<0.05)$ after $6 \pm 3$ weeks. The invasively assessed pressure gradient at rest was reduced from $63.7 \pm 15.2$ to $21.2 \pm 11.1 \mathrm{mmHg}(P<0.01)$ and the postextrasystolic gradient was reduced from $138.9 \pm 12.7$ to $45.6 \pm 16.5 \mathrm{mmHg}(P<0.01)$. All differences as well as the quantity of injected ethanol were plotted against the size or amount of scar tissue as assessed in the MRI. There was a statistically significant correlation between the post-extrasystolic gradient decrease and the amount of scar tissue $\left(P=0.03, r^{2}=0.5\right)$. In addition, the correlation between the quantity of ethanol and scar tissue area was highly significant $\left(P<0.01, r^{2}=0.6\right)$, whereas the values for the gradient deviation $\left(P=0.10, r^{2}=0.34\right), \Delta V_{\max }(P=0.12$, $\left.r^{2}=0.31\right)$, as well as the gradient at rest $(P=0.27$, $\left.r^{2}=0.17\right)$ were not significant.

Conclusion TASH was consistently effective in reducing the gradient in all patients with HOCM. In contrast to the variables investigated by echocardiography, the invasively measured post-extrasystolic gradient correlated much better with the amount of scar tissue as assessed by CMR. We conclude that the optimal modality to visualize the TASH effect seems to be a combination of CMR and the invasive identification of the post-extrasystolic gradient.

Keywords HOCM · TASH $\cdot$ CMR $\cdot$ Cardiac imaging
Abbreviations
HOCM Hypertrophic obstructive cardiomyopathy
TASH Transcoronary ablation of septal hypertrophy
CMR Cardiac MRI
LVOT Left ventricular outflow tract
$V_{\max } \quad$ Flux acceleration over the aortic valve 


$\begin{array}{ll}\text { RBBB } & \text { Right bundle branch block } \\ \text { LVEF } & \text { Left ventricular ejection fraction } \\ \text { CK } & \text { Creatine kinase } \\ \text { CAD } & \text { Coronary artery disease }\end{array}$

\section{Introduction}

Hypertrophic obstructive cardiomyopathy (HOCM) is a relatively common genetic cardiovascular disease with a prevalence of $\sim 1: 500$ [1]. Patients with HOCM often present with symptoms of heart failure and insufficient response to medical treatment [2-5]. The most frequent therapy applied to these patients is surgical myectomy (removing a small amount of myocardium from the basal interventricular septum) [6-9]. This substantially reduces the subaortic outflow gradient in more than $90 \%$ of patients and results in persistent symptomatic improvement in about $70-90 \%$ [2, 5, 7-10]. In the last few years, minimally invasive transcoronary ablation of septal hypertrophy (TASH) by selective transcatheter septal branch injection of ethanol has shown to reduce substantially outflow tract obstruction in $80-90 \%$ and reduction of symptoms in 84$90 \%$ of the treated patients [11-19]. Consequently, TASH may be an effective alternative to surgery [20-27]. To avoid collateral damage like right bundle branch block (RBBB) or high-grade atrioventricular block it is important to estimate the anatomical conditions before starting the intervention. Therefore, the purpose of the present study was to visualize the feasibility, hemodynamical success, and short term results of TASH on the basis of intracardiac catheterization, cardiac MRI (CMR), and echocardiography before and after the TASH procedure.

\section{Materials and methods}

To visualize the feasibility, hemodynamic success, and short term results of TASH intracardiac catheterization, CMR and echocardiography were conducted at baseline and in follow-up studies after 1, 3, and 12 months following the TASH procedure. All patients were monitored in the intensive or coronary care unit for at least $48 \mathrm{~h}$. ECG and cardiac enzyme controls were assessed every $4 \mathrm{~h}$ until the CK peak was reached. Before discharge, noninvasive follow-up included Doppler assessments of the residual LVOT gradient.

Patient inclusion

TASH was applied to nine patients (median age $62 \pm 6$ years, six females and three males) with HOCM. The diagnosis of HOCM was based on the common clinical
Table 1 Clinical characteristics of nine patients undergoing catheterbased treatment for HOCM by TASH

\begin{tabular}{ll}
\hline Patient characteristics & \\
\hline Total no. of patients & 9 \\
Male/female sex no. & $3 / 6$ \\
Age (years) & $62 \pm 6$ \\
Septum thickness $(\mathrm{mm})$ & $22.0 \pm 1.2$ \\
Echocardiographic pressure gradient $(\mathrm{mmHg})$ & $69.3 \pm 15.3$ \\
Echocardiographic flux acceleration $\left(\mathrm{V}_{\max }\right)(\mathrm{m} / \mathrm{s})$ & $5.1 \pm 0.6$ \\
Invasive gradient at rest $(\mathrm{mmHg})$ & $63.7 \pm 15.2$ \\
Invasive postextrasystolic gradient $(\mathrm{mmHg})$ & $138.9 \pm 12.7$ \\
Ethanol injection $(\mathrm{ml})$ & $1.8 \pm 0.3$ \\
\hline
\end{tabular}

and two-dimensional echocardiographic criteria [1]. Obstruction was defined by an LVOT gradient under resting conditions and after provocation of at least $30 \mathrm{mmHg}$ [1]. Detailed patients' characteristics are presented in the Table 1. A written informed consent was obtained from each patient.

\section{Echocardiographic examination}

Transthoracic and transesophageal echocardiography was performed on Philips Sonos 5500 (Philips Medical Systems) and recorded on an S-VHS video to allow serial review and side-by-side comparison of the studies. Standard probes were used for transthoracic and transesophageal echocardiography. Basal ventricular septal thickness was divided from an integrated analysis of M-mode and twodimensional echocardiograms. The M-mode echocardiograms were derived from direct anatomical visualization of the two-dimensional images. All measurements were made according to the recommendations of the American Society of Echocardiography [28]. The two-dimensional echocardiographic images were obtained in the parasternal longand short-axis views and apical two- and four-chamber views using standard transducer positions. For transesophageal acquisition, the probe was placed in the mid-esophageal position, where an adequate four-chamber view could be obtained. Short-axis views were derived from a basal gastric position. Care was taken to achieve a similar probe position for the follow-up examinations. Systolic anterior motion of the mitral valve was defined as mild, moderate or severe according to Gilbert et al. [29]. Echocardiographic examinations were conduced at baseline, $6 \pm 3$ weeks, 3 months, and 1 year after TASH.

\section{TASH procedure}

In each case, the gradient at rest and the post-extrasystolic gradient were measured before and after the procedure. 
Briefly, a suitable proximal branch of the left anterior descending coronary artery was identified by a gradientguided technique under programmed electrical stimulation. By using this technique, significantly smaller amounts of ethanol could be used by titrating the ethanol dose according to the angiographic washout velocity and real-time measured reduction of the intraventricular pressure gradient. Programmed electrical stimulation was used to provoke premature ventricular beats under reproducible conditions to assess post-extrasystolic potentiation of the gradient. Using this technique the fixed coupling interval is followed by an identical duration of the left ventricular filling period and a constant magnitude of the subsequently provoked gradient which correlates significantly with the gradient after physical exercise $[23,30]$. Ethanol was injected only in case of a clear reduction of the gradient during testing the effect of a transient balloon occlusion of the septal vessel.

\section{CMR investigation}

CMR was carried out $10 \pm 4$ weeks after TASH. MR imaging was performed on a 1.5-T scanner (Magnetom; Siemens, Germany) with 40-mT/m maximum gradient strength and a phased array body coil. Investigation time was about 30-40 min. Patients were studied in a supine position with breath-holding-technique. Short-axis cine MRI of the entire left ventricle from the base to the apex was performed for the analysis of cardiac mass and function. Heart rate, vectorcardiogram and blood pressure were monitored.

The left ventricular function was assessed by a segmented two-dimensional electrocardiographically triggered fast low-angle shot-pulse sequence in the cine mode (TR $23.8 \mathrm{~ms}$, TE $1.49 \mathrm{~ms}$, flip angle $59^{\circ}$, basic resolution $256 \times 256$, voxel size $2.0 \mathrm{~mm} \times 1.6 \mathrm{~mm} \times 5 \mathrm{~mm}$, slice thickness $5 \mathrm{~mm}$, chronological resolution $50 \mathrm{~ms}$, field of view phase $81.3 \%$, phase resolution $79 \%$, distance factor $20 \%$ and field of view reading up to $500 \mathrm{~mm}$ ). The number of cardiac phases imaged depended on the heart rate. Typically, 16 phases per cardiac cycle were obtained. Three short-axis planes were obtained; slice positions were taken from the cine MR imaging data set. The basal slice was the first to show circumferential myocardium at both diastole and systole. The apical slice was the last to show the intracavity blood pool in all phases over the cardiac cycle. The mid-ventricular slice was positioned halfway between the basal slice and the apical slice.

The left ventricular ejection fraction (LVEF) was estimated from the short-axis planes. Therefore, a segmented two-dimensional electrocardiographically triggered fast low-angle shot-pulse sequence was used during breathholding (TR $23.8 \mathrm{~ms}$, TE $1.49 \mathrm{~ms}$, flip angle $59^{\circ}$, basic resolution $256 \times 256$, voxel size $2.0 \mathrm{~mm} \times 1.6 \mathrm{~mm} \times$ $5 \mathrm{~mm}$, slice thickness $5 \mathrm{~mm}$, chronological resolution
$50 \mathrm{~ms}$, field of view phase $81.3 \%$, phase resolution $79 \%$, distance factor $20 \%$ and field of view reading up to $500 \mathrm{~mm}$ ). The number of cardiac phases imaged depended on the heart rate.

Image analysis

Tagged images were processed using the semiautomatic ARGUS software (version 2004 A; Siemens, Germany) and were evaluated by an attending thoracic radiologist and cardiologist. The area of interest was the ventricular septum and the subaortic region. The endo- and epicardial contours were defined in the end-diastolic frame and the software then detected the tag grid using an affine plus anisotropic radial scaling transform algorithm. The grid was adapted to each of the acquired images from the enddiastolic to the end-systolic frame, mass, left and right ventricular ejection fraction. If necessary, manual correction was performed by moving, adding, or deleting tag intersections. Evaluation time for tracking the tag intersections of one slice was about $30 \mathrm{~min}$.

Left ventricular function and mass was also analyzed. After the determination of the end-diastolic and end-systolic frame on the first basal slice to show circumferential myocardium at both diastole and systole, the endocardial and epicardial contours were traced manually by two investigators. The papillary muscles were included in the measured ventricular volume. To account for body height and mass, indexes were calculated related to $1 \mathrm{~m}^{2}$ of body surface area for volumes and masses. Parameters of global function of the left ventricle were end-diastolic and endsystolic volume index and ejection fraction. The ventricular mass index was obtained by the multiplication of the mean wall volume of the end-diastolic and the end-systolic frames and the specific weight of cardiac muscle (1.05 $\mathrm{g} / \mathrm{mL}$ ). All volumes were calculated automatically by summing the areas in the entire series of short-axis cine images.

Data analysis and statistics

All data are expressed as mean \pm SEM. Student's paired $t$ test was used to test for significance. $P<0.05$ was considered significant. A linear regression analysis was used for comparing gradient data and ethanol injection with myocardial scar tissue. GraphPad Prism 5 was used to perform the regression analysis and Microsoft Excel was used in the case of paired $t$ test of normal distributed data.

\section{Results}

TASH was highly effective in improving hemodynamic and anatomic conditions. Figure 1 shows the differences in 
Fig. 1 Effectiveness of the

TASH procedure.

a Echocardiographic

examination of the LVOT

gradient at rest, $\mathbf{b}$ the flux

acceleration $\left(V_{\max }\right)$ over the

aortic valve and $\mathbf{c}$ septum

thickness before and after

TASH. d Broadening of scar tissue by CMR. Invasive cardiac catheter examination of $\mathbf{e}$ the basal pressure gradient and $\mathbf{f}$ the post-extrasystolic gradient before and after TASH.

$* P<0.05, * * P<0.01$ versus before TASH, respectively
A

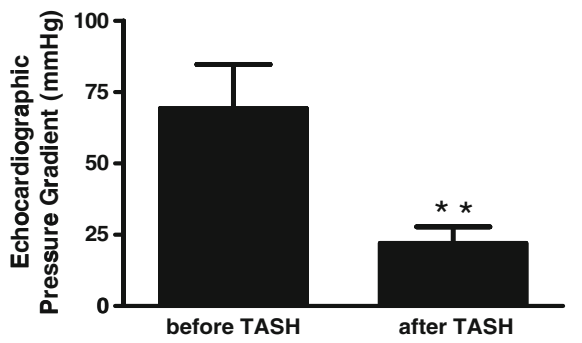

C
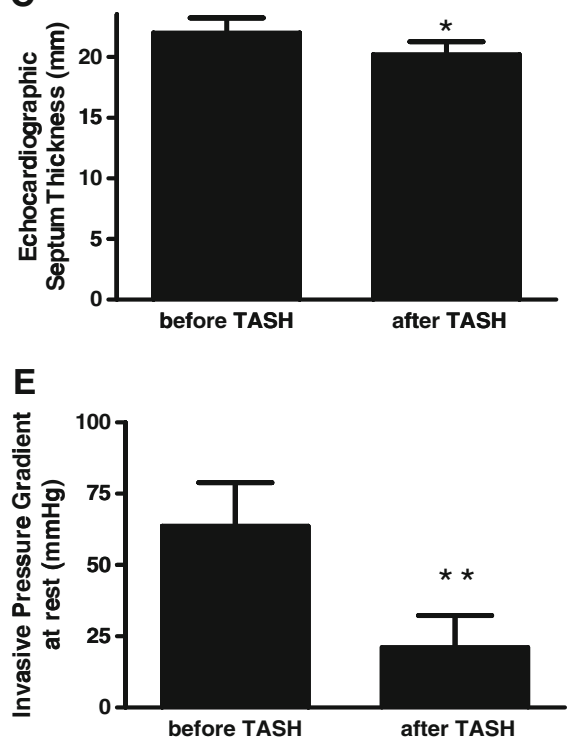

B

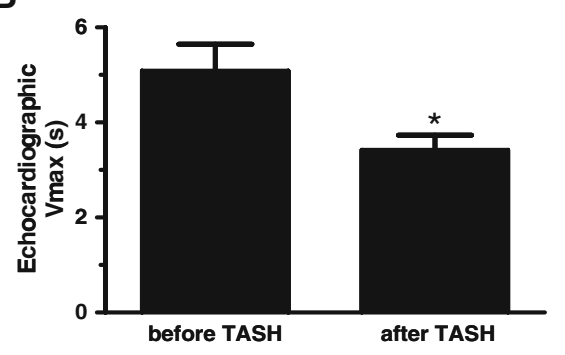

D

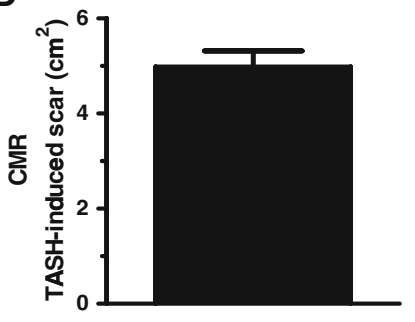

F

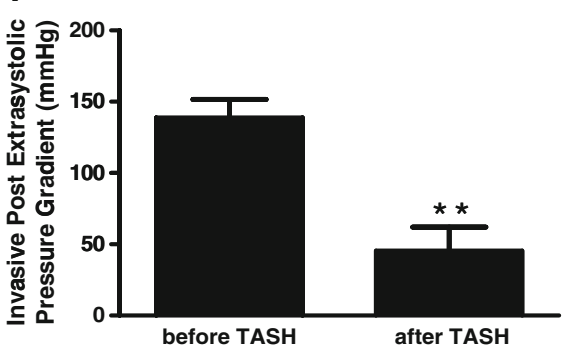

LVOT gradient, flux acceleration $\left(V_{\max }\right)$, septum thickness, pressure gradient at rest, post-extrasystolic gradient before and after TASH, as well as the corresponding scar tissue.

The echocardiographic pressure gradient could be significantly reduced by the TASH intervention. The LVOT gradient was reduced from $69.3 \pm 15.3$ to $22.1 \pm 5.7 \mathrm{mmHg}$ (Fig. 1a, $n=9$ patients each, $P<0.01$ ). Moreover, $V_{\max }$ was decreased from $5.1 \pm 0.6$ to $3.4 \pm 0.3 \mathrm{~m} / \mathrm{s}$ (Fig. 1b, $P<0.05$ ). There was a decrease of septum thickness from $22.0 \pm 1.2$ to $20.2 \pm 1.0 \mathrm{~mm}$ (Fig. $1, P<0.05$ ).

After the successful TASH procedure the scar tissue was appraised by CMR. The mean scar tissue area was $5.0 \pm 0.3 \mathrm{~cm}^{2}$ (Fig. 1d). The intracardiac catheter delivers the corresponding gradients in situ. The invasively assessed LVOT pressure gradient at rest was decreased from $63.7 \pm 15.2$ to $21.2 \pm 11.1 \mathrm{mmHg}$ (Fig. $1 \mathrm{e}, P<0.01$ ), and the post-extrasystolic gradient was reduced from $138.9 \pm 12.7$ to $45.6 \pm 16.5 \mathrm{mmHg}$ (Fig. 1f, $P<0.01$ ).

To further visualize the operability and success of TASH the echocardiographic and invasive measurements were correlated with the accordant CMR scar tissue area into the ventricular septum in the subaortic region. Figure 2 demonstrates the correlation between the scar size and the echocardiographically and invasively assessed parameters. Figure $2 \mathrm{~d}$ demonstrates a significant correlation between the scar size and the invasively measured post-extrasystolic gradient reduction $\left(P<0.05, r^{2}=0.5\right)$, whereas the values for the echocardiographic gradient deviation (Fig. 2a, $P=0.10, r^{2}=0.34$ ), $\Delta V_{\max }$ (Fig. 2b, $P=0.12$, $r^{2}=0.31$ ), as well as the invasive gradient at rest (Fig. 2c, $\left.P=0.27, r^{2}=0.17\right)$ were not significant. To evaluate the different effects of varying ethanol dosing within the procedure, the CMR scar tissue area was correlated with the quantity of injected ethanol. Our data showed a significant correlation between the amount of ethanol and the scar tissue (Fig. 3, $P<0.01, r^{2}=0.6$ ).

\section{Discussion}

In 1995, Sigwart et al. [12] were the first to describe the effect of occluding a septal perforator artery with ethanol on the pressure gradient in HOCM. This procedure provoked a localized septal infarction and was referred to as nonsurgical septal reduction therapy (NSRT). Subsequently, two German centers reported extensive experience with many hundreds of patients [13, 31]. Seggewiss et al. [31] have 
Fig. 2 Correlation between effectiveness of TASH and scar tissue. a Echocardiographic LVOT gradient deviation at rest, $\mathbf{b}$ flux acceleration reduction $\left(\Delta V_{\max }\right)$, c Decrease of the angiographic basal gradient and $\mathbf{d}$ postextrasystolic gradient correlated to the CMR scar tissue
A

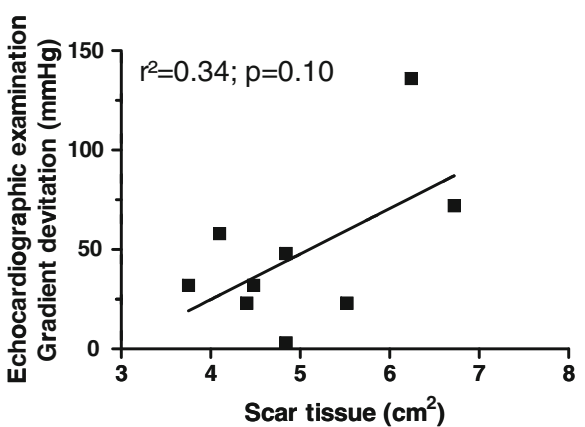

C

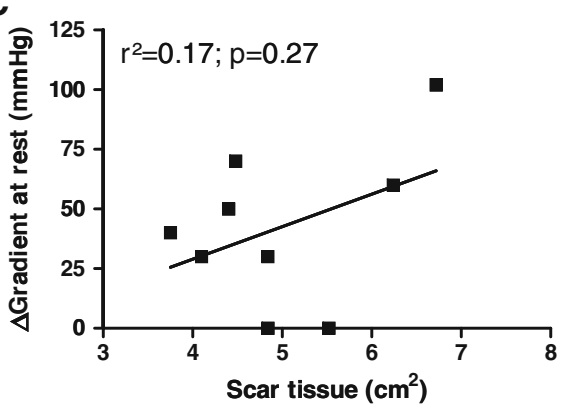

B

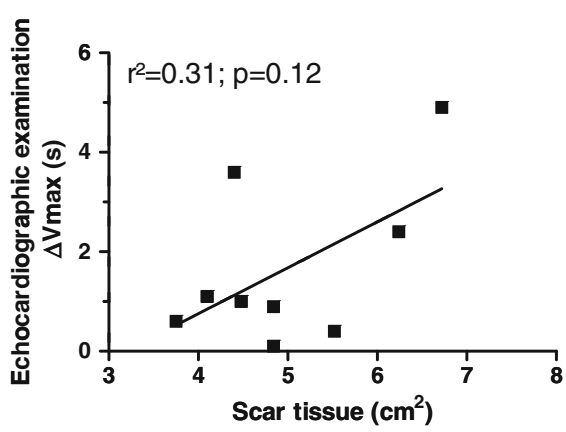

D

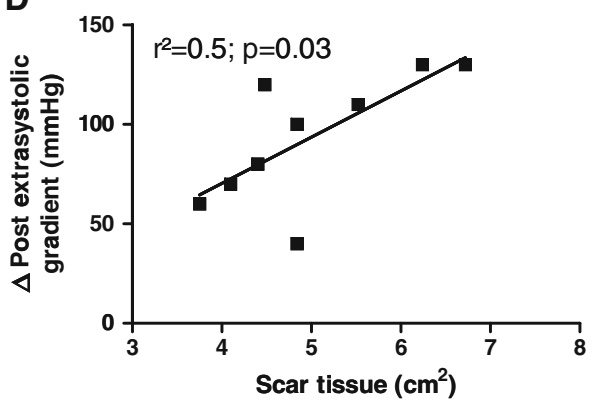

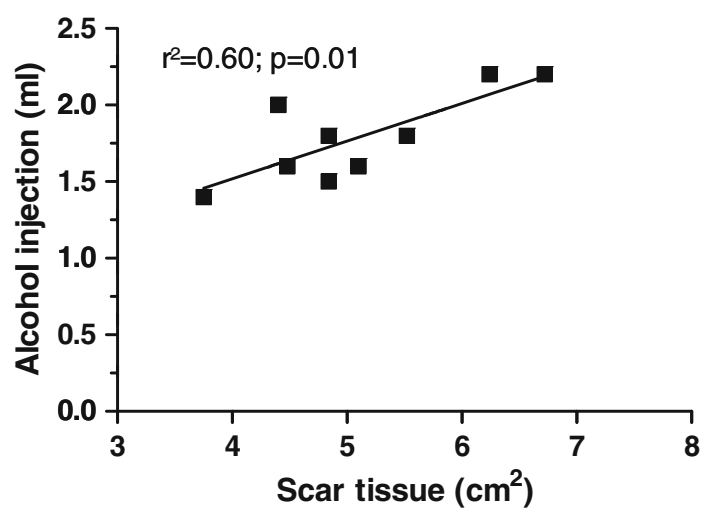

Fig. 3 Correlation between quantity of injected ethanol and the CMR scar tissue

referred to the procedure as percutaneous transluminal septal myocardial ablation (PTSMA), whereas Gietzen et al. $[13,27]$ have called the procedure transcoronary ablation of septal hypertrophy (TASH). There is enough evidence to show that the amount of ethanol used and the number of septal perforator arteries ablated determine the height of the creatine kinase (CK) rise, the degree of acute gradient reduction (Fig. 4) and the incidence of complete heart block and mortality $[13,17,27,31]$. The introduction of myocardial contrast echocardiography by Faber et al. [16] allows for the correct identification of the appropriate septal perforator to be occluded and the avoidance of occluding septal perforators that supply distant areas of the myocardium such as the papillary muscles or the free wall of the left or right ventricle. However, it has been shown that the amount of septum reduction increases further with time after TASH [32]. The observation that there is further gradient reduction in the year following the procedure has led to a less aggressive approach in terms of the amount of ethanol used and the number of vessels ablated during the procedure with a resulting decrease in the incidence of heart block [13, 17, 20, 27, 31, 32].

The TASH procedure is a promising nonsurgical technique for the reduction of symptoms and the LVOT gradient in HOCM. Several studies have shown clinical success rates with TASH application, varying from 90 to $100 \%[13,15,18,20,31,32]$. This is in line with our findings. Our results demonstrate a clinical success rate defined as a reduction of the echocardiographic LVOT gradient at rest, septum thickness, invasively assessed gradient at rest and gradient after stimulation of $100 \%$ (Fig. 1). The invasive measurements showed a significant decrease of the basal LVOT gradient at rest and also of the post-extrasystolic gradient after the TASH procedure (Figs. 1, 4). The echocardiographic examination of the LVOT gradient under basal conditions, the maximal flux acceleration over the aortic valve and septum size before and after TASH treatment confirms these results (Fig. 1). We could show a TASH-associated improvement in all examinations. Consequently, TASH was highly effective in improving hemodynamic and anatomic conditions. Furthermore, the TASH procedure has some advantages in comparison to myectomy surgery. These advantages include: the avoidance of cardiopulmonary bypass with 
Fig. 4 A 50-year-old male patient with HOCM and TASH. a Angiography protocol before TASH showing a postextrasystolic gradient at rest of $150 \mathrm{mmHg}$. b After the procedure the post-extrasystolic gradient is documented as maximal $40 \mathrm{mmHg}$
A

A
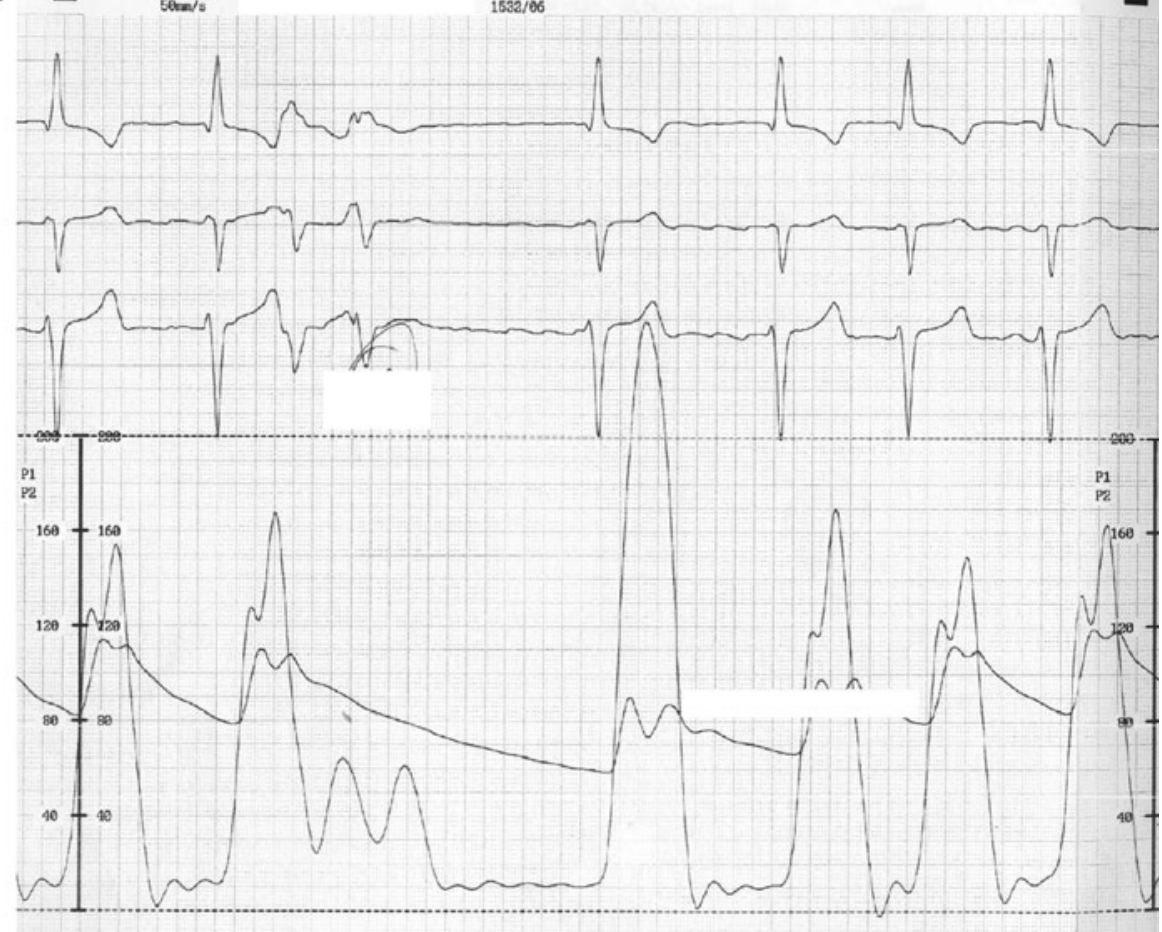

B

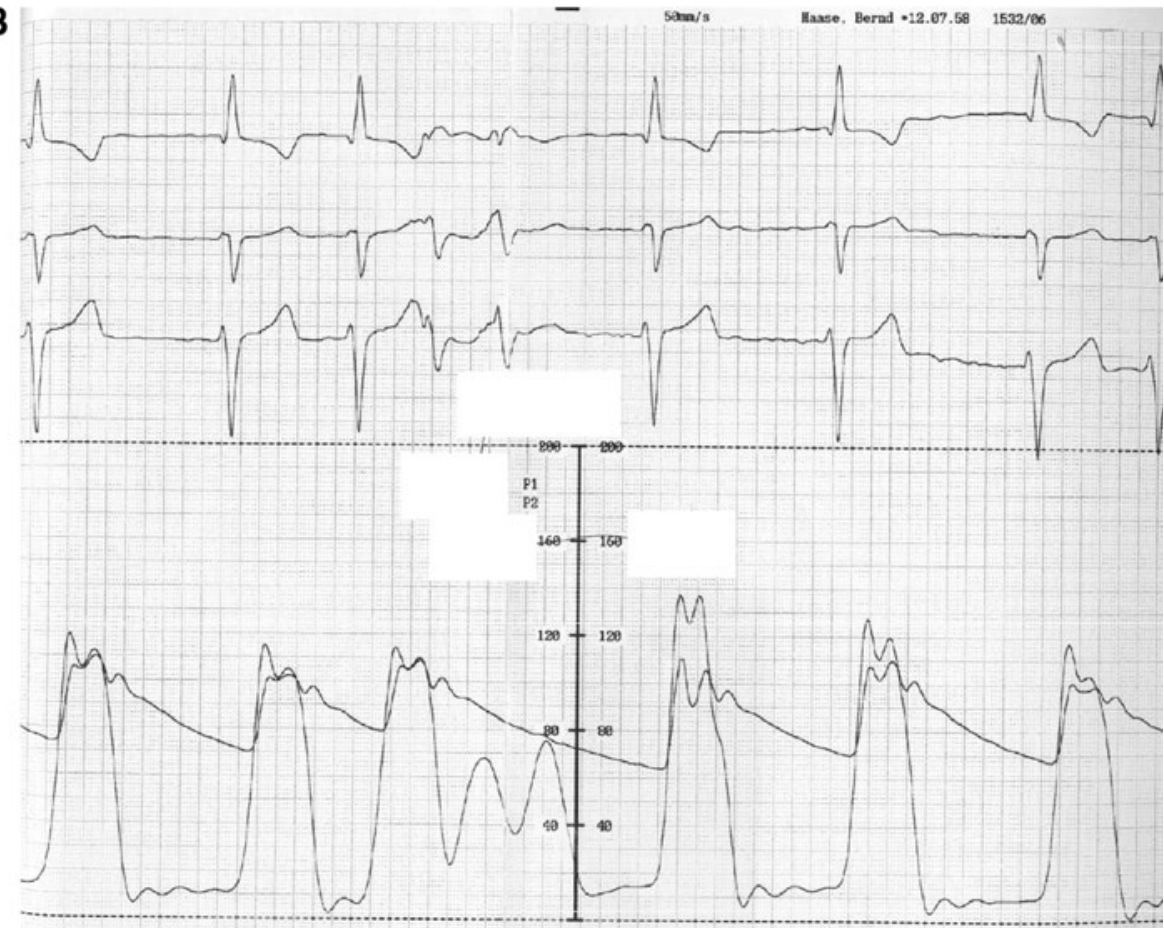

attendant risks, especially in elderly patients, as well as a shorter hospitalization period. Although two large German studies reported longer hospital residencies for supervision for delayed heart block [13, 31], a shorter recovery time and less expenses were recorded.

On the other hand, the advantages of myectomy surgery include: more immediate and complete relief of resting and provoked obstruction and concomitant mitral regurgitation, as well as smaller incidences of complete heart block, requiring a pacemaker. There are excellent long-term results with no risk of coronary dissection or unwanted myocardial infarction. There is no evidence in long-term studies that myectomy is arrhythmogenic, has ability to deal with concomitant problems such as mid-ventricular 
Fig. 5 An 82-year-old female patient with HOCM. MRI at four-chamber view (a, c, e) and at three-chamber view $(\mathbf{b}, \mathbf{d}, \mathbf{f})$ before $(\mathbf{a}, \mathbf{b})$ and after TASH

$(\mathbf{c}, \mathbf{d}, \mathbf{e}, \mathbf{f})$. a, $\mathbf{c}$ and $\mathbf{e}$ In each case late enhancement pictures after intravenous contrast medium injection. In the fourchamber view confirmation of scar tissue in the septum area $(\mathbf{c}, \mathbf{e}) . \mathbf{b}, \mathbf{d}$ and $\mathbf{f}$ in each case pictures in cine mode in the three-chamber view with SAM phenomenon which impresses slightly declining
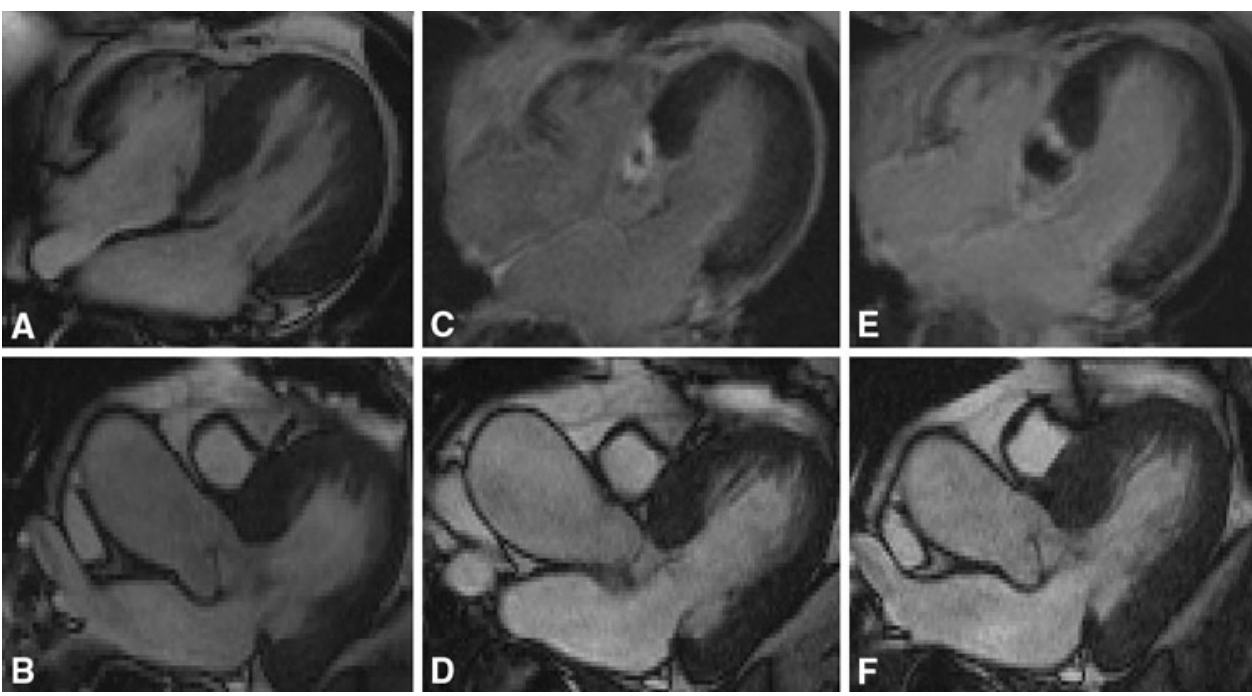

obstruction, constricting muscle bridges over the left anterior descending coronary artery, and aortocoronary bypass surgery. It does not cause right ventricular outflow obstruction, mitral valve repair or replacement for additional valvular problems, and concerning a small but significant amount of patients, it is not able to carry out NSRT for technical reasons, and NSRT may be less effective in younger patients with thicker septum [33] and in other specific circumstances

There is still a considerable debate on the optimal procedure in the management of subaortic obstructive HCM. On the one hand the ambition of TASH is the reduction of symptoms and the LVOT gradient in HOCM. On the other hand it is essential to reduce the collateral complications of the nonsurgical procedure like RBBB (in almost $50 \%$ of the patients) and high-grade atrioventricular block requiring permanent pacing in $10 \%$ [34]. Therefore, it is important to create a small-sized infarction-area. The role of CMR was to estimate the anatomical conditions before starting the intervention and to clarify the broadening of scar tissue. In our opinion, the current role and future potential of CMR in TASH has not been investigated sufficiently. It is accepted that CMR is the gold standard imaging tool to access cardiac masses or to measure cardiac scar tissue [35-39]. Furthermore, CMR has an outstanding role in ischemia diagnostic and coronary artery disease (CAD) [40-49]. To our knowledge this is the first study that shows a direct correlation of the CMR scar tissue and the effectiveness of TASH.

One aim of this study was to evaluate the ideal diagnostic imaging modality to illustrate the effectiveness of the TASH procedure. Another aim was to assess if the broadening of the infarction area correlates with the reduction of the LVOT gradient. After the successful TASH procedure the scar tissue was appraised by CMR and the infarction area was correlated with the decrease of the LVOT gradient the septum downsizing and the ethanol injection. Figure 2 shows a correlation between each examination and the corresponding scar tissue. There was no significant correlation between the echocardiographic investigations and the corresponding scar tissue into the CMR investigation. Consequently, echocardiography may not be able to visualize the effectiveness of TASH significantly. Concerning the invasive measurements, Fig. $2 \mathrm{c}$ also delivers a nonsignificant result for the correlation of the angiographic LVOT gradient at rest and the imaged infarction area. In Fig. $2 \mathrm{~d}$ the post-extrasystolic gradient is plotted against the scar tissue. There was a statistical significant correlation between the different investigation methods $(P=0.03$, $\left.r^{2}=0.5\right)$. Furthermore, our results suggest some answers in the remaining areas of uncertainty concerning the different effects of varying ethanol dosing within TASH. Veselka et al. [50], compared the effect of a "high dose" $(2.8 \pm 0.6 \mathrm{ml})$ versus a "low dose" $(1.5 \pm 0.4 \mathrm{ml})$ of ethanol, resulting in $\mathrm{CK}$ peaks of about six- versus ninefold above their upper reference value of $0.4 \mathrm{Kat} / 1$. As the main conclusion, no difference was found with respect to hemodynamic efficiency during short-term follow-up in 42 patients. This is in concert with several other studies which suggest, that a correctly placed ablation lesion, releasing a CK peak of five- to nine-fold, should be high enough to substantially reduce or eliminate the LVOT obstruction during a 12-month local remodeling process [27, 51, 52]. In our study, the mean amount of ethanol injected was $1.8 \pm 0.3 \mathrm{ml}$ (Table 1). The results of our study show a significant correlation between the amount of injected ethanol and scar tissue investigated by CMR (Fig. 3, $P=0.01$, $\left.r^{2}=0.6\right)$. Consequently, these data underline the outstanding importance of the correctly placed TASH procedure. Our analysis clarifies the ability of CMR to deliver a direct in vivo evaluation of the ethanol associated infarction area (Figs. 5, 6). Thus, it offers an independent alternative to laboratory testing and other imaging techniques. 

patient with HOCM. a septum nose before and $\mathbf{b}$ after the TASH procedure, with reduction of the marked areas
Fig. 6 A 68-year-old female
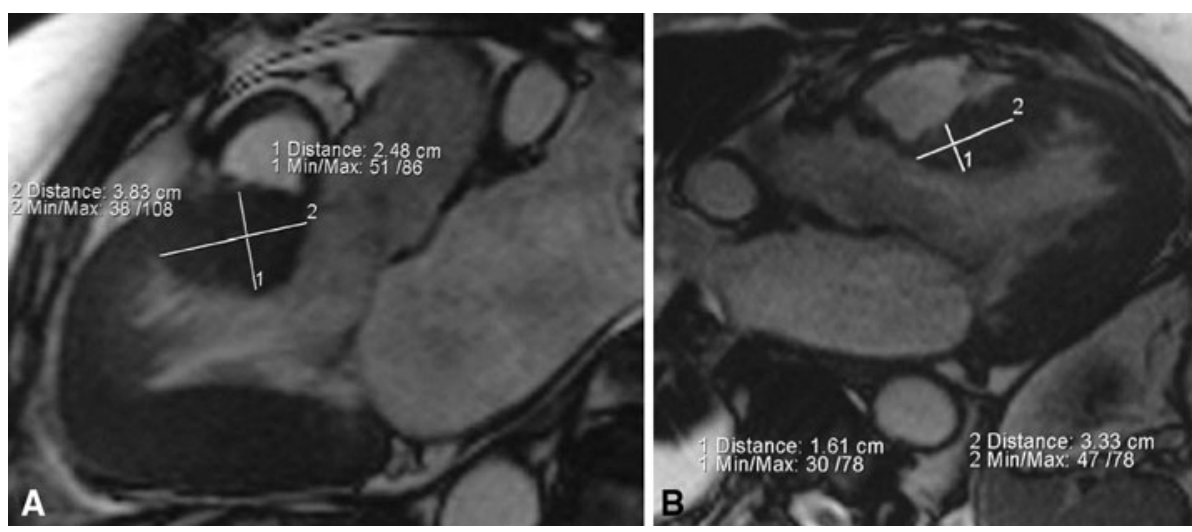

Fig. 7 A 78-year-old male patient with each MR investigation into cine mode before TASH. a SAM phenomenon, $\mathbf{b}, \mathbf{c}$ and $\mathbf{d}$. Measurement of dimensions, $\mathbf{b}$ at three-chamber view, $\mathbf{c}$ at short axis (end-systolic) and $\mathbf{d}$ at short axis (end-diastolic)

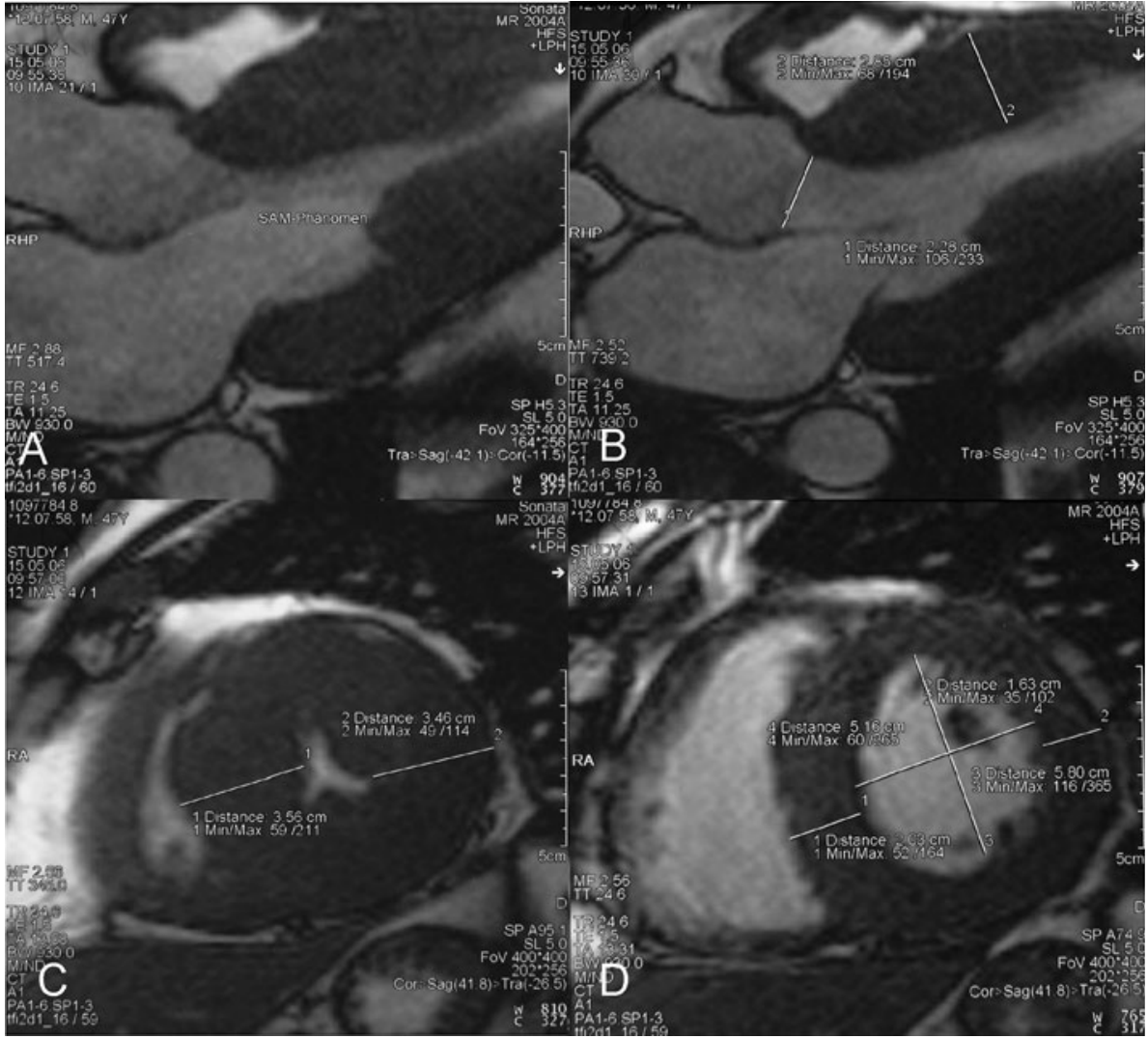

This indicates that a combined technique of invasive measurements and noninvasive CMR is ideally suited to assess the efficiency of TASH in ventricular hypertrophy and remodeling, which may allow a reduction in sample size to show clinically relevant effects. A comprehensive functional assessment is possible by CMR because of its capability to measure the flow velocity and the flow volume, which are the basic requirements to quantify lesion severity in a heart disease, which was formerly the main focus of echocardiography (Fig. 7) [35, 36, 40]. Another important advantage of CMR over other imaging methods that are used to assess myocardial viability is that it shows the transmural extent of viable myocardium (Fig. 5) [41]. This leads to the possibility of visualizing the ethanol determined infarction area as scar tissue. Furthermore, major technical advances have considerably improved acquisition speed and image quality thus making CMR a useful tool for the evaluation of patients with ischemic heart disease [42-49].

Our study has several limitations. It has to be considered that there is only a relative small study population which leads to high range of individual variability. Probably, some results would have reached statistical significant correlation with a greater amount of patients. Patients were 
not assigned randomly. Larger studies with more patients have to be conducted. The M-mode measurements of left atrial and left ventricular dimensions may not sample exactly maximum and minimum wall thickness, may be subject to angle errors, and were not performed blinded with respect to treatment status.

We come to the conclusion that CMR offers a potentially more accurate noninvasive technique for in vivo comparison of scar tissue than echocardiography. Furthermore, CMR provides images with high spatial resolution, free of geometric constraints, as well as precise volumetric quantification of abnormalities and direct anatomical correlation (Figs. 5, 6). We conclude that, the optimal modality to visualize the TASH effect seems to be a combination between CMR-imaging and the invasive identification of the post-extrasystolic gradient.

Acknowledgments Prof. Maier is funded by the Deutsche Forschungsgemeinschaft (DFG) through grants for a Clinical Research group (MA 1982/2-2) and by a DFG Heisenberg grant (MA 1982/4-1).

Open Access This article is distributed under the terms of the Creative Commons Attribution Noncommercial License which permits any noncommercial use, distribution, and reproduction in any medium, provided the original author(s) and source are credited.

\section{References}

1. Maron BJ, McKenna WJ, Danielson GK, Kappenberger LJ, Kuhn HJ, Seidman CE, Shah PM, Spencer WH, Spirito P, Ten Cate FJ, Wigle ED (2003) ACC/ESC clinical expert consensus document on hypertrophic cardiomyopathy: a report of the American College of Cardiology Task Force on Clinical Expert Consensus Documents and the European Society of Cardiology Committee for Practice Guidelines. J Am Coll Cardiol 42:1687-1713

2. Loogen F, Kuhn H, Gietzen F, Loesse B, Schulte HD, Bircks W (1983) Clinical course and prognosis of patients with typical and atypical hypertrophic obstructive and with hypertrophic nonobstructive cardiomyopathy. Eur Heart J 4:145-153

3. Maron BJ, Bonow RO, Cannon RO 3rd, Leon MB, Epstein SE (1987) Hypertrophic cardiomyopathy: interrelations of clinical manifestations, pathophysiology, and therapy (1). N Engl J Med 316:780-789

4. Wigle ED, Rakowski H, Kimball BP, Williams WG (1995) Hypertrophic cardiomyopathy: clinical spectrum and treatment. Circulation 92:1680-1692

5. Spirito P, Seidman CE, McKenna WJ, Maron BJ (1997) The management of hypertrophic cardiomyopathy. N Engl J Med 336:775-785

6. Morrow AG, Reitz BA, Epstein SE, Henry WL, Conkle DM, Itsoitz SB, Redwood DR (1975) Operative treatment in hypertrophic subaortic stenosis: techniques, and the results of pre and postoperative assessments in 83 patients. Circulation 52: 88-102

7. Maron BJ, Epstein SE, Morrow AG (1983) Symptomatic status and prognosis of patients after operation for hypertrophic obstructive cardiomyopathy: efficacy of ventricular septal myotomy and myectomy. Eur Heart J 4(suppl F):175-185
8. Schulte HD, Borisov K, Gams E, Gramsch-Zabel H, Loesse B, Schwartzkopff B (1999) Management of symptomatic hypertrophic obstructive cardiomyopathy: long-term results after surgical therapy. Thorac Cardiovasc Surg 47:213-218

9. Robbins RC, Stinson EB (1996) Long-term results of left ventricular myotomy and myectomy for obstructive hypertrophic cardiomyopathy. J Thorac Cardiovasc Surg 111:586-594

10. Maron BJ, Bonow RO, Cannon RO 3rd, Leon MB, Epstein SE (1987) Hypertrophic cardiomyopathy: interrelations of clinical manifestations, pathophysiology, and therapy (2). N Engl J Med 316:844-852

11. Kuhn H, Gietzen F, Ch Leuner, Gerenkamp T (1997) Induction of subaortic septal ischaemia to reduce obstruction in hypertrophic obstructive cardiomyopathy: studies to develop a new catheterbased concept of treatment. Eur Heart J 18:846-851

12. Sigwart U (1995) Non-surgical myocardial reduction for hypertrophic obstructive cardiomyopathy. Lancet 346:211-214

13. Gietzen FH, ChJ Leuner, Raute-Kreinsen U, Dellmann A, Hegselmann J, Strunk-Mueller C, Kuhn HJ (1999) Acute and long-term results after transcoronary ablation of septal hypertrophy (TASH): catheter interventional treatment for hypertrophic obstructive cardiomyopathy. Eur Heart J 20:1342-1354

14. Kuhn H, Gietzen FH, Schäfers M, Freick M, Gockel B, StrunkMüller C, Jachmann E, Schober O (1999) Changes in the left ventricular outflow tract after transcoronary ablation of septal hypertrophy (TASH) for hypertrophic obstructive cardiomyopathy as assessed by transoesophageal echocardiography and by measuring myocardial glucose utilization and perfusion. Eur Heart J 20:1808-1817

15. Knight C, Kurbaan AS, Seggewiss H, Henein M, Gunning M, Harrington D, Fassbender D, Gleichmann U, Ul Sigwart (1997) Nonsurgical septal reduction for hypertrophic obstructive cardiomyopathy: outcome in the first series of patients. Circulation 95:2075-2081

16. Faber L, Seggewiss H, Gleichmann U (1998) Percutaneous transluminal septal myocardial ablation in hypertrophic obstructive cardiomyopathy: results with respect to intraprocedural myocardial contrast echocardiography. Circulation 98:2415-2421

17. Lakkis NM, Nagueh SF, Kleimann NS, Killip D, He ZX, Verani MS, Roberts R, Spencer WH 3rd (1998) Echocardiographyguided ethanol septal reduction for hypertrophic obstructive cardiomyopathy. Circulation 98:1750-1755

18. Boekstegers P, Steinbigler P, Molnar A, Schwaiblmair M, Becker A, Knez A, Haberl R, Steinbeck G (2001) Pressure-guided nonsurgical myocardial reduction induced by small septal infarctions in hypertrophic obstructive cardiomyopathy. J Am Coll Cardiol 38:846-853

19. Mazur W, Nagueh SF, Lakkis NM, Middelton KJ, Killip D, Roberts R, Spencer WH 3rd (2001) Regression of left ventricular hypertrophy after nonsurgical septal reduction therapy for hypertrophic obstructive cardiomyopathy. Circulation 103:14921496

20. Nagueh SF, Ommen SR, Lakkis NM, Killip D, Zoghbi WA, Schaff HV, Danielson GK, Quinones MA, Tajik AJ, Spencer WH (2001) Comparison of ethanol septal reduction therapy with surgical myectomy for the treatment of hypertrophic obstructive cardiomyopathy. J Am Coll Cardiol 38:1701-1706

21. Wigle ED, Schwartz L, Woo A, Rakowski H (2001) To ablate or operate? That is the question!. J Am Coll Cardiol 38:1707-1710

22. Fananapazir L, McAreavey D (1998) Therapeutic options in patients with obstructive hypertrophic cardiomyopathy and severe drug-refractory symptoms. J Am Coll Cardiol 31:259-264

23. Kuhn H, Gietzen FH, Leuner C, Schäfers M, Schober O, StrunkMüller C, Obergassel L, Freick M, Gockel B, Lieder F, RauteKreinsen U (2000) Transcoronary ablation of septal hypertrophy 
(TASH): a new treatment option for hypertrophic obstructive cardiomyopathy. Z Kardiol 89(4):41-54

24. Spirito P, Maron BJ (1999) Perspectives on the role of new treatment strategies in hypertrophic obstructive cardiomyopathy. J Am Coll Cardiol 33:1071-1075

25. Maron BJ (1999) New interventions for obstructive hypertrophic cardiomyopathy: promise and prudence. Eur Heart J 20:1292-1294

26. Braunwald E (2002) Hypertrophic cardiomyopathy: the benefits of a multidisciplinary approach. N Engl J Med 347:1306-1307

27. Kuhn H, Lawrenz LiederF, Leuner C, Strunk-Müller C, Obergassel L, Bartelsmaer M, Stellbrink C (2008) Survival after transcoronary ablation of septal hypertrophy in hypertrophic obstructive cardiomyopathy (TASH): a 10 year experience. Clin Res Cardiol 97:234-243

28. Sahn DJ, De Maria A, Kisslo J, Weymann A (1978) Recommendations regarding quantitation in M-mode echocardiography: results of a survey of echocardiographic measurements. Circulation 58:1072-1083

29. Gilbert BW, Pollick C, Adelman AG, Wigle ED (1980) Hypertrophic cardiomyopathy: subclassification by M-mode echocardiography. Am J Cardiol 45:861-872

30. Klues HG, Leuner C, Kuhn H (1992) Left ventricular outflow tract obstruction in patients with hypertrophic cardiomyopathy: increase in gradient after exercise. J Am Coll Cardiol 19:527-533

31. Seggewiss H, Faber L, Gleichmann U (1999) Percutaneous transluminal septal ablation in hypertrophic obstruction cardiomyopathy. Thorac Cardiovasc Surg 47:94-100

32. Alam M, Dokainish H, Lakkis N (2006) Alcohol septal ablation for hypertrophic obstructive cardiomyopathy: a systematic review of published studies. J Interven Cardiol 19:319-327

33. Seggewiss H, Faber L, Ziemssen P (2000) Age related acute results of percutaneous septal ablation in hypertrophic obstructive cardiomyopathy (abstract). J Am Coll Cardiol 35(Suppl A):188A

34. Sathyamurthy I (2006) Transcoronary ablation of septal hypertrophy (TASH). Indian Heart J 58:371-374

35. Watzinger N, Maier R, Reiter U, Reiter G, Fuernau G, Wonisch M, Fruhwald FM, Schumacher M, Zweiker R, Rienmueller R, Klein W (2005) Clinical applications of cardiovascular magnetic resonance. Curr Pharm Des 11:457-475

36. Bernhardt P, Engels T, Knuf B, Strohm O (2006) Cardiac magnetic resonance in outpatients in Germany-indications, complications and protocol suggestions from a high-volume center. Int $\mathbf{J}$ Cardiol 28(111):86-91

37. Schroeder J, Peterschroeder A, Vaske B, Butz T, Barth P, Oldenburg O, Bitter T, Burchert W, Horstkotte D, Langer C (2009) Cardiac volumetry in patients with heart failure and reduced ejection fraction: a comparative study correlating multislice computed tomography and magnetic resonance tomography; reasons for intermodal disagreement. Clin Res Cardiol 98:739-747

38. Pilz G, Bernhardt P, Harrer E, Klos M, Höfling B (2008) Cardiac magnetic resonance imaging: an essential diagnostic aid in suspected myocardial re-infarction in a 40 year old woman. Clin Res Cardiol 97:280-283

39. Schwab J, Haack G, Sinss D, Bär I, Zahn R (2007) Diagnosis of left ventricular myxoma with cardiac magnetic resonance imaging. Clin Res Cardiol 96:189-190
40. Altbach MI, Squire SW, Kudithipudi V, Castellano L, Sorrell VL (2007) Cardiac MRI is complementary to echocardiography in the assessment of cardiac masses. Echocardiography 24:286-300

41. Kim RJ, Wu E, Rafael A, Chen EL, Parker MA, Simonetti O, Klocke FJ, Bonow RO, Judd RM (2000) The use of contrastenhanced magnetic resonance imaging to identify reversible myocardial dysfunction. N Engl J Med 343:1445-1453

42. Nandalur KR, Dwamena BA, Choudhri AF, Nandalur MR, Carlos RC (2007) Diagnostic performance of stress cardiac magnetic resonance imaging in the detection of coronary artery disease: a meta-analysis. J Am Coll Cardiol 50:1343-1353

43. Baer FM, Thiessen P, Schneider CA, Voth E, Sechtem U, Schichta H (1998) Dobutamine magnetic resonance imaging predicts contractile recovery of chronically dysfunctional myocardium after successful revascularisation. J Am Coll Cardiol 31:1040-1048

44. Wellhofer E, Olariu A, Klein C, Grafe M, Wahl A, Fleck E, Nagel E (2004) Magnetic resonance low-dose dobutamine test is superior to SCAR quantification for the prediction of functional recovery. Circulation 109:2172-2174

45. Gotte MJ, van Rossum AC, Twisk JWR, Kuijer JPA, Marcus JT, Visser CA (2001) Quantification of regional contractile function after infarction: strain analysis superior to wall thickening analysis in discriminating infarct from remote myocardium. J Am Coll Cardiol 37:808-817

46. Plein S, Kozerke S, Suder D, Luescher TF, Greenwood JP, Boesiger P, Schwittler J (2008) High spatial resolution myocardial perfusion cardiac magnetic resonance for the detection of coronary artery disease. Eur Heart $\mathbf{J}$ (Epub ahead of print)

47. Merkle N, Wöhrle J, Nusser T, Grebe O, Spiess J, Torzewski J, Hombach V (2009) Diagnostic performance of magnetic resonance first pass perfusion imaging is equally potent in female compared to male patients with coronary artery disease. Clin Res Cardiol, Sep 11 (Epub ahead of print)

48. Jensen CJ, Bleckmann D, Eberle HC, Nassenstein K, Schlosser T, Sabin GV, Naber CK, Bruder O (2009) A simple MR algorithm for estimation of myocardial salvage following acute ST segment elevation myocardial infarction. Clin Res Cardiol 98:651-656

49. Doesch C, Seeger A, Hoevelborn T, Klumpp B, Fenchel M, Kramer U, Schönfisch B, Claussen CD, Gawaz M, Miller S, May AE (2008) Adenosine stress cardiac magnetic resonance imaging for the assessment of ischemic heart disease. Clin Res Cardiol 97:905-912

50. Veselka J, Duchonová R, Procházková S, Pálenícková J, Sorajja P, Tesar D (2005) Effects of varying ethanol dosing in percutaneous septal ablation for obstructive hypertrophic cardiomyopathy on early hemodynamic changes. Am J Cardiol 95:675-678

51. Faber L, Welge D, Fassbender D, Schmidt HK, Horstkotte D, Seggewiss H (2007) One-year follow-up of percutaneous septal ablation for symptomatic hypertrophic obstructive cardiomyopathy in 312 patients: predictors of hemodynamic and clinical response. Clin Res Cardiol 96:864-873

52. Lawrenz T, Lieder F, Leuner CJ, Obergassel L, Gockel B, Strunk-Mueller C, Kuhn H (2003) What is the correct amount of ethanol in the catheter based treatment for hypertrophic obstructive cardiomyopathy? Eur Heart J 24(Suppl):136 